7Niniejsza publikacja jest dostępna na licencji Creative Commons. Uznanie autorstwa-Użycie niekomercyjne-Bez utworów zależnych 3.0 Polska. Pewne prawa zastrzeżone na rzecz autora. Zezwala się na wykorzystanie publikacji zgodnie z licencja - pod warunkiem zachowania niniejszej informacji licencyjnej oraz wskazania autora jako wtaściciela praw do tekstu. Treść licencji jest dostęnna na stronie: http://creativecommons.org/licenses/by-nc-nd/3.0/pl/

Lingwistyka Stosowana 23: 3/2017, 39-46

Mirosław GAJER

AGH Akademia Górniczo-Hutnicza

\title{
Analiza zagadnień związanych z próbami odczytania dysku z Fajstos w kontekście występowania na jego powierzchni zagadkowych wzorów geometrycznych
}

\begin{abstract}
:
Analysis of the issues related to decipherment of the Phaistos disc in the presence of mysterious geometrical patterns appearing on its surface

The Phaistos disc is a well-known archeological artifact that was found by the Italian scientist Luigi Pernier in 1908 during his excavations in Crete in the ruins of the Minoan palace close to the town of Phaistos. It is believed that the Phaistos disc contains a natural language text written with the use of some kind of a syllabic script. In such a context it seems considerably unusual that some geometrical patterns can be observed on the surface of the side A of the Phaistos disc. The aim of the paper is to try to answer the question whether it is possible that such compound geometrical patterns could appear at random during the process of writing. For this reason, the author has developed a theoretical probabilistic model and conducted some Monte Carlo simulations. The findings strongly suggest that the geometrical patterns were made intentionally and for this reason it is highly possible that the Phaistos disc does not contain any natural language text at all. Thus the results of the conducted research seem to yield convincing evidence to support the argument that this artifact may be a forgery.
\end{abstract}

\section{Wstęp}

Słynny dysk z Fajstos jest powszechnie znanym zabytkiem archeologicznym związanym z obszarem starożytnej kultury minojskiej (zob. J. Chadwick 1998). Rozważany artefakt został odnaleziony 3 lipca 1908 roku przez włoskiego archeologa L. Perniera podczas prowadzonych przez jego ekipę badawczą wykopalisk w ruinach minojskiego pałacu w miejscowości Fajstos na Krecie (zob. J. Ciechanowicz 1996).

W środowisku naukowym dysk z Fajstos jest powszechnie uważany za obiekt autentyczny, pochodzący z początków drugiego tysiąclecia p.n.e. (zob. Y. Duhoux 2000). Również wśród badaczy dość powszechnie przyjmuje się, że dysk z Fajstos zawiera pewien tekst zapisany $\mathrm{w}$ jakimś nieustalonym jak dotychczas języku naturalnym, w związku z czym wszelkie wysiłki koncentrują się zwykle na próbach odczytania zawartych tam informacji (zob. A. Bradshaw 1977). Tymczasem uzyskane przez autora niniejszego artykułu wyniki pozwalają na poddanie w wątpliwość, czy 
w przypadku dysku z Fajstos istotnie mamy do czynienia z tekstem zapisanym w jakimkolwiek języku naturalnym (zob. M. Gajer 2008).

Szczegółowe omówienie zagadnień związanych z odnalezieniem dysku z Fajstos, jego datowaniem, hipotezami dotyczącymi jego przeznaczenia i próbami odczytania można znaleźć, między innymi, we wcześniej opublikowanej pracy autora (zob. M. Gajer 2017), w związku z czym tego rodzaju informacje w niniejszym artykule nie będą powtarzane.

Autor niniejszego artykułu w swej uprzednio opublikowanej pracy (zob. M. Gajer 2017) zwrócił także uwagę na istnienie znacznych różnic dotyczących charakterystyk statystycznych tekstu, które zostały wyznaczone odrębnie dla strony A i strony B dysku z Fajstos. Tego rodzaju anomalie statystyczne nie są bynajmniej typowe dla innych standardowych tekstów zapisanych w różnych językach świata pismem sylabicznym, co stawia pod dużym znakiem zapytania hipotezę, w myśl której na dysku z Fajstos znajduje się w ogóle jakikolwiek tekst zapisany w pewnym języku naturalnym (zob. M.P. Jackson1999).

Ponadto niezwykle intrygujące wydają się swego rodzaju wzory geometryczne, w które układają się niektóre ze znaków odciśniętych na powierzchni dysku z Fajstos (zob. M.P. Jackson 2000). W tym miejscu niejako w sposób automatyczny nasuwa się pytanie, czy tego rodzaju wzory geometryczne mogły powstać w sposób spontaniczny podczas pisania tekstu, czy też zostały utworzone w sposób intencjonalny (zob. W. Reczko 2009).

\section{Wzory geometryczne na powierzchni dysku z Fajstos}

W opinii autora w przypadku dysku z Fajstos najbardziej zastanawiające są liczne wzory geometryczne, które można dostrzec zwłaszcza na jego stronie A (zob. A. Kondratow 1988). Na przykład, na stronie A dysku z Fajstos znak przedstawiający głowę wojownika w hełmie z pióropuszem (znak nr 2) w dwóch miejscach, pokazanych na rysunku 1, zdaje się tworzyć dwa odcinki linii prostej, z których każdy składa się z trzech tego typu znaków, ułożonych jeden nad drugim w kolejnych zwojach linii spiralnej (zob. A.T. Cate 2011).

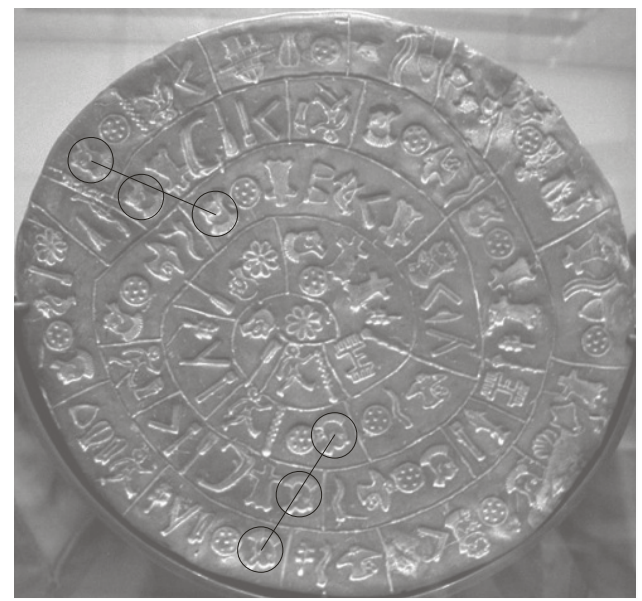

Rysunek 1. Zaznaczone na stronie A dysku z Fajstos dwa odcinki linii prostej wyznaczone przez trzy umieszczone kolejno jeden nad drugim znaki nr 2 (opracowanie własne). 
Podobnie, w dwóch innych miejscach na stronie A dysku z Fajstos grupy trzech znaków przedstawiających wizerunek wygarbowanej wołowej skóry (znak nr 27) tworzą dwa trójkąty zbliżone swym kształtem do trójkątów prostokątnych, co zostało pokazane na rysunku 2.

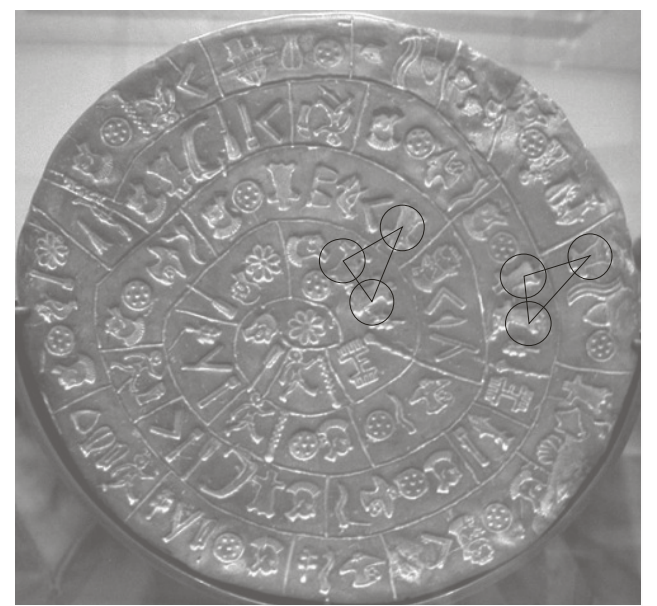

Rysunek 2. Zaznaczone na stronie A dysku z Fajstos dwa trójkąty wyznaczone przez trzy umieszczone w swoim bezpośrednim sasiedztwie znaki nr 27 (opracowanie własne).

Jednak najbardziej zagadkowym w swej postaci wzorem geometrycznym, występującym na stronie A dysku z Fajstos, jest w miarę regularny siedmiokąt, zbliżony swym kształtem do siedmiokąta foremnego, w którego wierzchołkach znajdują się znaki przedstawiające wizerunek tarczy (znak nr 12). Rozważana figura geometryczna, przypominająca swym kształtem siedmiokąt foremny, została uwidoczniona na rysunku 3.

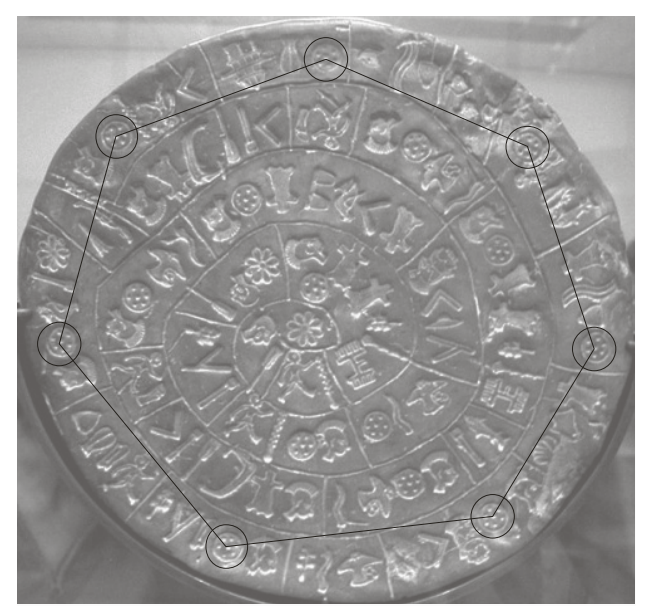

Rysunek 3. Zaznaczony na stronie A dysku z Fajstos siedmiokat, zbliżony w swym ksztatcie do siedmiokata foremnego, w którego wierzchotkach tkwiq znaki nr 12 (opracowanie własne).

Lingwistyka Stosowana/ Applied Linguistics/ Angewandte Linguistik: www.ls.uw.edu.pl 
$\mathrm{Na}$ podstawie analizy przedstawionych na rysunkach 1-3 wzorów geometrycznych nasuwa się niezwykle ważne pytanie, które dotyczy tego, czy twory te są wyłącznie dziełem przypadku, czy też zostały, być może, sporządzone w sposób intencjonalny. Zwłaszcza w przypadku zamieszczonego na rysunku 3 siedmiokąta o wysoce regularnym kształcie można powątpiewać, czy tego rodzaju, mimo wszystko dość złożony, wzór geometryczny mógł pojawić się na brzegu dysku z Fajstos wyłącznie jako efekt swego rodzaju niezmiernie rzadkiego zbiegu okoliczności (zob. A.T. Cate 2013) .

W celu wyrobienia sobie poglądu na, bez wątpienia, niezwykłość tego rodzaju fenomenu można wyobrazić sobie pewien tekst zapisany alfabetem łacińskim w jakimś języku naturalnym (przykładowo angielskim), w którym, dajmy na to, co siódma litera byłaby, załóżmy, literą „e”. Oczywiście, wymyślenie tego rodzaju tekstu w języku angielskim jest zapewne jak najbardziej możliwe, ale gdyby rozważany tekst miał jeszcze mieć jakieś sensowne znaczenie, sprawa z pewnością o wiele bardziej się komplikuje.

Spróbujmy zatem udzielić odpowiedzi na pytanie, jak wysokie jest prawdopodobieństwo zdarzenia, że występujący na brzegu dysku z Fajstos siedmiokąt foremny jest wyłącznie dziełem przypadku i nie został utworzony w sposób intencjonalny. Będzie to zarazem naszą hipotezą zerową.

\section{Szacowanie wartości prawdopodobieństwa pojawienia się siedmiokąta}

W celu oszacowania wartości prawdopodobieństwa zdarzenia, polegającego na tym, że na brzegu strony A dysku z Fajstos w sposób całkowicie losowy pojawił się siedmiokąt o kształcie zbliżonym do siedmiokąta foremnego, należy najpierw opracować odpowiedni model probabilistyczny.

Po pierwsze, zauważmy, że na brzegu strony A dysku z Fajstos znajduje się dokładnie 49 znaków odciśniętych w glinie. W tabeli 1 podano numery kolejnych znaków, przyjęte zgodnie $\mathrm{z}$ powszechnie obowiązującą w badaniach nad dyskiem $\mathrm{z}$ Fajstos konwencją. Interesujący nas znak nr 12, przedstawiający prawdopodobnie wizerunek tarczy, został uwypuklony poprzez wyszarzenie tła i pogrubienie czcionki.

\begin{tabular}{|l|l|l|l|l|l|l|}
\hline 02 & $\mathbf{1 2}$ & 13 & 01 & 18 & 24 & 40 \\
\hline $\mathbf{1 2}$ & 29 & 45 & 07 & 29 & 29 & 34 \\
\hline 02 & $\mathbf{1 2}$ & 04 & 40 & 33 & 27 & 45 \\
\hline 07 & $\mathbf{1 2}$ & 27 & 44 & 08 & 02 & $\mathbf{1 2}$ \\
\hline 06 & 18 & 31 & 26 & 35 & 02 & $\mathbf{1 2}$ \\
\hline 41 & 19 & 35 & 01 & 41 & 40 & 07 \\
\hline 02 & $\mathbf{1 2}$ & 32 & 23 & 38 & 39 & 11 \\
\hline
\end{tabular}

Tabela 1. Numery kolejnych 49 znaków odciśniętych na brzegu strony A dysku z Fajstos (opracowanie wtasne).

Jak wynika z zawartości tabeli 1, znaki nr 12 zajmują odpowiednio pozycje znakowe o numerach: $2,8,16,23,28,35$ i 44. W związku z powyższym odległości pomiędzy kolejnymi znakami nr 12 wynoszą odpowiednio; 6, 8, 7, 5, 7 i 9 pozycji 
znakowych, w związku z czym średnia odległość pomiędzy kolejnymi znakami nr 12 wynosi dokładnie 7 pozycji znakowych.

Nie popełniając zapewne większego błędu, można w celu uproszczenia dalszych rozważań przyjąć nieco wyidealizowany model brzegu strony A dysku z Fajstos zakładając, że wszystkie odciśnięte tam znaki mają do siebie bardzo zbliżone wymiary. W takim wypadku siedmiokąt foremny powstanie, gdy kolejne znaki nr 12 będą zajmować na brzegu dysku pozycje znakowe o numerach, odpowiednio: 1, 8, $15,22,29,36$ i 43, co zostało pokazane na rysunku 6 .

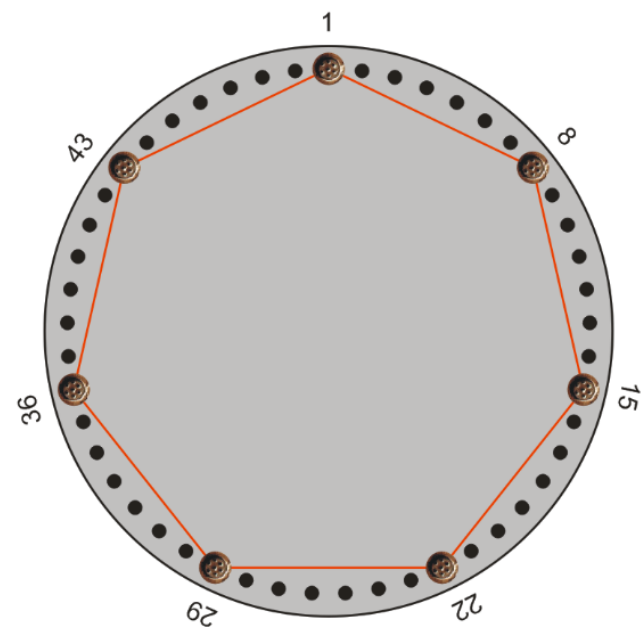

Rysunek 4. Siedmiokąt foremny o wierzchołkach umieszczonych w pozycjach znakowych o numerach: $1,8,15,22,29,36$ i 43 (opracowanie własne).

Spróbujmy zatem odpowiedzieć na pytanie, na ile różnych sposobów można zrealizować przedstawiony na rysunku 4 siedmiokąt foremny. Po pierwsze, należy zauważyć, że w wyróżnionych pozycjach znakowych o numerach: 1, 8, 15, 22, 29, 36 i 43, niekoniecznie musi znajdować się 7 znaków nr 12, ponieważ wystarczy, aby w wymienionych pozycjach było dokładnie 7 identycznych znaków dowolnego typu. Ponieważ dysk z Fajstos zawiera 45 różnych typów znaków, daje to dokładnie 45 możliwości wyboru znaku, który znajdzie się w wierzchołkach siedmiokąta foremnego.

Jeżeli już dokonamy wyboru znaku, w oparciu o który ma zostać utworzony siedmiokąt foremny, pozostałe 42 znaki mogą być już całkowicie dowolne, co daje łącznie $45^{42}$, czyli około $2,722 \cdot 10^{69}$ możliwości wyboru.

Ponadto należy uwzględnić to, że rozważany siedmiokąt foremny może także podlegać dodatkowym rotacjom. Przykładowo, siedmiokąt foremny powstanie również, gdy identyczne znaki pojawią się w pozycjach przesuniętych o jedno miejsce w prawo, czyli: 2, 9, 16, 23, 30, 37 i 44. W sumie, uwzględniając możliwości dodatkowych rotacji siedmiokąta foremnego, istnieje 7 dalszych kombinacji rozmieszczenia poszczególnych znaków, co pokazano w tabeli 2. 


\begin{tabular}{|l|c|c|c|c|c|c|}
\hline 1 & 8 & 15 & 22 & 29 & 36 & 43 \\
\hline 2 & 9 & 16 & 23 & 30 & 37 & 44 \\
\hline 3 & 10 & 17 & 24 & 31 & 38 & 45 \\
\hline 4 & 11 & 18 & 25 & 32 & 39 & 46 \\
\hline 5 & 12 & 19 & 26 & 33 & 40 & 47 \\
\hline 6 & 13 & 20 & 27 & 34 & 41 & 48 \\
\hline 7 & 14 & 21 & 28 & 35 & 42 & 49 \\
\hline
\end{tabular}

Tabela 2. Numery pozycji znakowych, w których musza znajdować się znaki identycznego typu, aby w efekcie zostat utworzony z nich siedmiokat foremny (opracowanie własne).

Ostatecznie liczba kombinacji rozmieszczenia 49 znaków, które prowadzą do powstania siedmiokąta foremnego, obliczana jest jako iloczyn uzyskanych uprzednio wartości, czyli 45,7 i $2,722 \cdot 10^{69}$, co w rezultacie końcowym daje wartość około $8,575 \cdot 10^{71}$.

Z kolei wszystkich możliwych sposobów rozmieszczenia znaków na brzegu dysku jest $45^{49}$, czyli istnieje w tym zakresie około $1,017 \cdot 10^{81}$ możliwości wyboru. W związku z powyższym prawdopodobieństwo losowego pojawienia się na brzegu dysku siedmiokąta foremnego może zostać wyznaczone jako iloraz uzyskanych uprzednio wartości, czyli $8,575 \cdot 10^{71}$ i $1,017 \cdot 10^{81}$, co daje w rezultacie wartość prawdopodobieństwa około $8,432 \cdot 10^{-10}$.

Reasumując, istnieje szansa nieco mniejsza niż jeden do miliarda, że siedmiokąt na brzegu dysku z Fajstos pojawił się w sposób całkowicie przypadkowy. W związku z otrzymaniem tak niezwykle małej wartości prawdopodobieństwa naszą hipotezę zerową należy bezwzględnie odrzucić. Pozostaje zatem do wyboru jedynie hipoteza alternatywna, czyli po prostu należy uznać, że siedmiokąt widniejący na brzegu strony A dysku z Fajstos pojawił się w sposób intencjonalny.

\section{Symulacje komputerowe typu Monte Carlo}

W celu eksperymentalnego potwierdzenia wyników uzyskanych powyżej na drodze czysto teoretycznych rozważań, autor postanowił przeprowadzić dodatkowo symulacje komputerowe typu Monte Carlo, czyli symulacje, których podstawę realizacji stanowią generowane przez odpowiedni program komputerowy ciągi liczb pseudolosowych.

Na potrzeby rozważanych symulacji brzeg dysku z Fajstos został zamodelowany w postaci jednowymiarowej tablicy, składającej się z 49 komórek, które mogą przechowywać wyłącznie liczby całkowite. Na początku każdej kolejnej iteracji opracowanego przez autora algorytmu symulacyjnego rozważana tablica była wypełniana liczbami pseudolosowymi z przedziału od zera do 44, przy czym kolejne komórki rozważanej tablicy zostały oznaczone odpowiednio jako: x[0], x[1], x[2], x[3], ... , $\mathrm{x}$ [46], $\mathrm{x}$ [47], x[48]. W kolejnym kroku dla poszczególnych elementów rozważanej tablicy sprawdzane było, czy spełniona jest następująca formuła logiczna:

$(x[0]=x[7] \quad$ AND $x[0]=x[14]$ AND $x[0]=x[21]$ AND $x[0]=x[28]$ AND $x[0]=x[35]$ AND $x[0]=x[42])$ OR

$(x[1]=x[8] \quad$ AND $x[1]=x[15]$ AND $x[1]=x[22]$ AND $x[1]=x[29]$ AND $x[1]=x[36]$ AND $x[1]=x[43])$ OR

$(x[2]=x[9] \quad A N D x[2]=x[16]$ AND $x[2]=x[23]$ AND $x[2]=x[30]$ AND $x[2]=x[37]$ AND $x[2]=x[44])$ OR

$(x[3]=x[10]$ AND $x[3]=x[17]$ AND $x[3]=x[24]$ AND $x[3]=x[31]$ AND $x[3]=x[38]$ AND $x[3]=x[45])$ OR 
$(x[4]=x[11]$ AND $x[4]=x[18]$ AND $x[4]=x[25]$ AND $x[4]=x[32]$ AND $x[4]=x[39]$ AND $x[4]=x[46])$ OR

$(x[5]=x[12]$ AND $x[5]=x[19]$ AND $x[5]=x[26]$ AND $x[5]=x[33]$ AND $x[5]=x[40]$ AND $x[5]=x[47])$ OR $(x[6]=x[13]$ AND $x[6]=x[20]$ AND $x[6]=x[27]$ AND $x[6]=x[34]$ AND $x[6]=x[41]$ AND $x[6]=x[48])$

Co istotne, spełnienie rozważanej formuły logicznej o, mimo wszystko, dość złożonej postaci jest równoważne $\mathrm{z}$ faktem pojawienia się na brzegu dysku przynajmniej jednego siedmiokąta foremnego, w którego poszczególnych wierzchołkach umieszczone są znaki należące do tego samego typu.

Odpowiedni program komputerowy został napisany przez autora w popularnym języku programowania $\mathrm{C}++\mathrm{i}$ następnie skomplikowany przy użyciu darmowego narzędzia Dev-C++. Przeprowadzono łącznie 10 miliardów iteracji rozważanego algorytmu symulacyjnego, podczas których zaobserwowano zaledwie cztery przypadki spełnienia zaprezentowanej powyżej formuły logicznej, co było tym samym równoznaczne $\mathrm{z}$ pojawieniem się siedmiokąta foremnego na brzegu zamodelowanego numerycznie dysku.

Jak widać, przeprowadzone przez autora symulacje komputerowe typu Monte Carlo potwierdziły uzyskane uprzednio rezultaty teoretyczne, co jeszcze raz stanowi niepodważalny dowód na intencjonalne wykonanie na dysku z Fajstos zagadkowych wzorów geometrycznych. Swego rodzaju barierę na drodze do szerszego zastosowania rozważanych symulacji typu Monte Carlo stanowi zwykle stosunkowo długi czas ich realizacji. W analizowanym przez autora przypadku wykonanie 10 miliardów iteracji algorytmu symulacyjnego zajęło około pięciu godzin pracy komputera klasy PC, taktowanego sygnałem zegarowym o częstotliwości 2,53 GHz (procesor dwurdzeniowy).

\section{Podsumowanie}

Przedstawione w artykule obliczenia probabilistyczne oraz przeprowadzone symulacje komputerowe typu Monte Carlo w sposób jednoznaczny dowodzą, że znajdujące się na dysku z Fajstos zagadkowe wzory geometryczne zostały utworzone w sposób intencjonalny i z pewnością nie są jedynie dziełem czystego przypadku. W związku z powyższym dysk z Fajstos nie może po prostu zawierać zwykłego tekstu o charakterze linearnym, ponieważ istnieją złożone związki zachodzące pomiędzy znakami zamieszczonymi na wyróżnionych pozycjach.

Powyższe spostrzeżenie jest niezwykle istotne z punktu widzenia oceny wiarygodności dotychczasowych prób odczytania dysku z Fajstos, ponieważ w sposób jednoznaczny pozwala zdefiniować całą klasę propozycji odczytania dysku z Fajstos, które z całą pewnością są błędne (zob. A.T. Cate 2011). Są to wszystkie propozycje jego odczytania, które nie uwzględniają tego typu zależności zachodzących pomiędzy znakami znajdującymi się niekiedy na dość odległych od siebie pozycjach. Ze względu na to, że żadna z przedstawionych do chwili obecnej propozycji odczytania dysku z Fajstos nie bierze w ogóle pod uwagę tego rodzaju zależności, propozycje te nie mogą być w żadnym wypadku traktowane jako poważne i muszą być postrzegane jedynie jako przykład nieokiełznanej wręcz fantazji ich autorów (zob. Y. Duhoux 2000). 
Ponadto w głębokim przekonaniu autora występowanie na dysku z Fajstos licznych wzorów geometrycznych pozwala wątpić, czy istotnie mamy tutaj do czynienia $\mathrm{z}$ jakimkolwiek tekstem $\mathrm{w}$ języku naturalnym, ponieważ celowe ułożenie tekstu, który tworzyłby rozważane wzory geometryczne i jednocześnie posiadał jakieś sensowne znaczenie byłoby zapewne niezwykle trudnym zadaniem.

Na zakończenie wypada jeszcze wspomnieć o hipotezie wysuniętej przez amerykańskiego eksperta do spraw fałszerstw starożytnych dzieł sztuki, J. Eisenberga, według którego dysk z Fajstos jest falsyfikatem utworzonym w celu zdobycia sławy i światowego rozgłosu przez jego odkrywcę (zob. J.M. Eisenberg 2008). Oczywiście w przypadku fałszerstwa nie należy spodziewać się, aby dysk z Fajstos zawierał w ogóle zapis jakiegokolwiek tekstu w jakimkolwiek języku, natomiast poszczególne znaki mogły zostać celowo ułożone w zagadkowe wzory geometryczne, aby obiekt ten wydawał się jeszcze bardziej niezwykły i tajemniczy.

\section{Bibliografia}

Bradshaw, A. (1977), The Overcuts on the Phaistos Disc, (w:) „Kadmos”, Vol. 16, Issue 2, 99-110.

Cate, A.T. (2011), Patterns on an Ancient Artifact: A coincidence?, (w:) ,Statistica Neerlandica" Vol. 65, Number 1, 116-124.

Cate, A.T. (2013), A Statistical Analysis of the Rotated Signs of the Phaistos Disc, (w:) „Pioneer Journal of Theoretical and Applied Statistics” Vol. 6, Number 2, 81-88.

Chadwick, J. (1998), Pismo linearne B, Warszawa, Wydawnictwo RTW.

Ciechanowicz, J. (1996), Cień Minotaura, Warszawa, Państwowy Instytut Wydawniczy.

Duhoux, Y. (2000), How Not to Decipher the Phaistos Disc: A Review, (w:) „American Journal of Archaeology", Number 104, 597-600.

Eisenberg, J.M. (2008), The Phaistos Disc: A one Hundred-Year-Old Hoax?, (w:) „Minerva”, July/August, 9-24.

Gajer, M. (2008), Zastosowanie metod lingwistyki komputerowej do analizy starożytnych inskrypcji, (w:) „Informatyka Teoretyczna i Stosowana”, rocznik 8, nr $14,53-62$.

Gajer, M. (2017), Czy zagadkowy dysk z Fajstos $w$ istocie zawiera odciśnięty w glinie zapis tekstu w pewnym języku naturalnym?, (w:) ,Lingwistyka Stosowana/ Applied Linguistics/ Angewandte Linguistik", tom 21, 23-37.

Jackson, M.P. (1999), A Statistical Study of the Phaistos Disc, (w:) „Kadmos”, Bd. 38, 19-30.

Jackson, M.P. (2000), Structural Parallelism on the Phaistos Disc. A Statistical Analysis, (w:) „Kadmos”, Bd. 39, 57-71.

Kondratow, A. (1988), Zaginione cywilizacje, Warszawa, Państwowy Instytut Wydawniczy.

Reczko, W. (2009), Analyzing and Dating the Structure of the Phaistos Disk, (w:) „Archaeological and Anthropological Sciences”, Number 1, 241-245. 